\title{
Ergonomic and Workload Assessment in Weeding Operation Conducted for Wheat Crop for Male Respondents
}

\author{
Vishnu Ji Awasthi ${ }^{*}$, Manpreet Singh², RajatMishra ${ }^{3}$, Rahul Chaudhary ${ }^{1}$, \\ Mirtunjay Pandey ${ }^{4}$, Dilwar Singh Parihar ${ }^{5}$, Shubham Gautam ${ }^{6}$ and Dhiraj Kumar ${ }^{7}$ \\ ${ }^{1}$ Farm Machinery and Power Engineering, VIEAT, Sam Higginbottom University of \\ Agriculture, Technology and Sciences, Prayagraj-211 007, UP, India \\ ${ }^{2}$ Farm Power and Machinery, Department of Farm Machinery and Power Engineering, \\ Punjab Agricultural University, Ludhiana-141 004, Punjab, India \\ ${ }^{3}$ Soil and Water Conservation Engineering, VSIAT, Sam Higginbottom University of \\ Agriculture, Technology and Sciences, Prayagraj-211 007, UP, India \\ ${ }^{4}$ Farm Machinery and Power Engineering, Faculty of Agricultural Engineering, Bidhan \\ Chandra KrishiVishwavidyalaya, Mohanpur, Nadia-741252, West Bengal, India \\ ${ }^{5}$ Farm Machinery and Power Engineering, CAE, Jawaharlal Nehru KrishiVishwaVidyala, \\ Jabalpur- 482 004, MP, India \\ ${ }^{6}$ Renewable Energy Engineering, VSIAT, Sam Higginbottom University of Agriculture, \\ Technology and Sciences, Prayagraj-211 007, UP, India \\ ${ }^{7}$ Soil and Water Conservation Engineering, IAS, Banaras Hindu University, Varanasi- 221 \\ 005, UP, India \\ *Corresponding author
}

\begin{tabular}{|l|}
\hline Ke y w o r d s \\
Physiological \\
variations, \\
anthropometric \\
dimensions, \\
VO2max \\
\hline Article Info \\
\hline $\begin{array}{l}\text { Accepted: } \\
\text { 24 August } 2019 \\
\text { Available Online: } \\
\text { 10 September } 2019\end{array}$ \\
\hline
\end{tabular}

A B S T R A C T
The present findings focuses on the assessment of anthropometrical, physical and physiological characteristics undergone by male operators during weeding operation. The variations were measured prior to and after the commencement of weeding activity. The VO2max and AWL was 27.59 $\mathrm{mL} / \mathrm{Kg}$ min and 9.61 respectively. Assessment of physiological parameters includes average resting heart rate of the respondents which was reckoned as $101.33 \mathrm{bpm}$. The average working heart rate during weeding activity in case of hand hoe and wheel hoe was 112.33 and 108.83 (bpm) respectively. The average EER and OCR values were $8.19 \mathrm{~kJ} / \mathrm{min}$ and $0.53 \mathrm{~L} / \mathrm{min}$ in case of hand hoe and for wheel hoe it was $7.88 \mathrm{~kJ} / \mathrm{min}$ and $0.51 \mathrm{~L} / \mathrm{min}$ respectively. The average BPDS of subjects were ascertained as 25.4and 21.4 for hand hoe and wheel hoe respectively. The subjects experienced light physical work in case of wheel hoe and moderately heavy physical work in hand hoe. 


\section{Introduction}

Agriculture offers the basic means of income for majority of Indian farmers. The workers use various types of tools, equipment's and machinery for their day to day activities in the agricultural fields. Use of proper tools provides effective and sonorous results and hence it becomes utmost necessary to consider the human factor in the design of farm tools to enhance the operating efficiencies, working comfort and thereby improving the productivity of workers. Ergonomically designed equipment's/tools enhance the human operating efficiencies and comfort during its operation. The ergonomics being the branch of science is applied in every of field since it involves the aspects of man, machine and working environment. It, therefore plays a vital role in every workplace with the factor mainly focussing on the level of ease and safety to the subjects performing the desired operation in a particular work layout. Every field of science is somehow interconnected with the prospects of ergonomics and its related extent. Agriculture is also closely related to it since it constitutes a way to bring man (operator), machine (implement) and working environment (field). It is an imperative measure of operator's performance in carrying out any agricultural operation. It is regarded as the application of anatomical, physiological and psychological knowledge in the man, machine and environment. The workers use various types of tools, equipment's and machinery for their day to day activities in the agricultural fields. Use of proper tools provides promising and encouraging results and hence it becomes utmost necessary to consider the human factor in the design of farm tools to enhance the operating efficiencies, working comfort and thereby improving the productivity of workers. In keeping a view of this, the concern research deals with the ergonomic evaluation of male operators in weeding operation which is performed by hand hoe (khurpa) and the wheel hoe. The performance of a weeder not only depends on the constructional features but also on the workers operating them. The performance of man-implement system may be poor, if ergonomics aspects are not given due attention. Tewari et al., (1991) stated that the performance of the weeder is interpreted in terms of weeding efficiency and the grade of work relates to rating of workload while worker' comfort is the subjective assessment of operating posture. The physiological cost of work includes the heart rate (HR), oxygen consumption rate (OCR) and energy expenditure rate (EER). Ease of performing an operation affects the output of the worker.

Ergonomic evaluation is a tool to evaluate the energy expenditure of work, their physiological cost and suitability of the method for farm workers and how long they can work continue without getting fatigue (Kumar A. et al.,2013). Hence, to address these concerns of ergonomics in the field of agriculture to provide safe and comfort to the farmers and operators, the major thrust of the research findings is to assess the physical and physiological responses resulting in addition to the anthropometric dimensions and body part discomfort for the operators engaged in the farm operation.

\section{Materials and Methods}

The study was conducted at Agricultural farms, Department of Farm Machinery \& Power Engineering, Vaugh Institute of Agricultural Engineering and Technology, Sam Higginbottom University of Agriculture, Science and Technology, Prayagraj (Allahabad).

The details of materials, procedures followed, and techniques adopted during the course of present investigation have been elaborated in this chapter under the following headings. 


\section{Experimental setup}

\section{Equipment employed for weeding activity which are taken into consideration}

\section{Hand hoe}

Hand hoe used in weeding operation is khurpa. It is traditional weeding and interculture tool. It essentially consists of a blade attached to a ferrule. The blade is used to uproot the weeds. It consists of a wooden handle to manipulate it according to its necessity. It is usually operated by the rural labours to perform the weeding operation. The work rate of hand hoe is about $0.01 \mathrm{ha} / \mathrm{hr}$.

\section{Wheel hoe}

It is a manually operated weeder mostly used by both male and female operators owing to its high work rate of $0.05 \mathrm{ha} / \mathrm{h}$. It consists of a single sharp tyne blade and a single wheel to move hoe to a desired direction. It is operated in a standing posture which renders the operator more mobile.

\section{Method - (In order to implement the} experimental plan)

The ergonomic study was conducted in Agricultural farms, SHUATS, Prayagraj and its nearby villages. The anthropometric data of the selected operators was measured during the study. Weeding operation was carried out by hand hoe i.e. khurpa and wheel hoe at the desired site prescribed in the field of wheat crop with row to row spacing $0.95 \mathrm{~m}$.

Sixty male respondents in the age group of 25 to 50 years (i.e. $20-25,25-30,30-35,35-40$, 40-45 and 45-50) were selected. The mentioned age interval comprises 10 respondents. The operators were chosen at random to perform weeding operation by hand hoe and wheel hoe. Different replications (3 replications) were taken for the subjects during their performance by the listed hoes. These replications are performed on different days and each trial by each subject for each implement was 30min duration.

The subjects were selected on the basis of range of various age to conduct the evaluation of the performance from ergonomic point of view.

The past history of the respondents was considered with the intent to obtain the sonorous results in the present research study. The subject was made well acquainted with the experimental protocol to achieve their full co-operation and to maintain the uniformity in the measurement. Proper co-ordination and a sort of collaboration was achieved with the subject.

Firstly, all the anthropometric measurement is taken including height, weight and other body parameters of different ages of the subject. After words they were allowed to perform the weeding operation by employing the mentioned hoes for a duration of $20 \mathrm{~min}$. Before the commencement of the weeding operation.

The physiological parameters of the subject were taken such as heart rate (maximum and minimum) heart rate and resting and working blood pressure (both Systolic and Diastolic) were measured at one-minute intervals after five minutes from the beginning of work.

After that, other variables whose values depends on above enlisted parameters including OCR, EER and $\mathrm{CCW}$ were calculated.

The same procedure was repeated to get three sets of trials or replications and the average of the three sets was used to achieve the rigorous readings. 
Physical, physiological and discomfort parameters involved in the concern study for the male subjects

\section{BMI}

The BMI is defined as the body mass divided by the square of the body height. The relation of BMI is given as:

\section{BMI $=$ Weight $/(\text { Height })^{2}-2.1$}

\section{LBM}

Lean body mass is a component of body composition, calculated by subtracting body fat weight from total body weight.

For male $-\mathrm{LBM}=(0.32810 * \mathrm{w})+$ $(0.33929 * \mathbf{H})-29.5336-2.2$

Estimation - LBM is usually estimated using the relation given by Hume, R (jul 1966).

\section{Weight}

The quantity of matter contained by the body is weight. Body weight of male and female subjects (in $\mathrm{Kg}$ ) of different ages is measured by employing calibrated weighing scale.

\section{Stature}

Stature is the vertical distance (in $\mathrm{cm}$ ) from the standing surface to the vertex of the head when the subject stands erect and looks straight forward.

\section{BMR}

Basal Metabolic Rate is the number of calories required to keep your body functioning at rest, also known as the metabolism. It is related to body mass, age, weight and height. It is also affected by gender. By Harris Benedict Equations,
BMR for male operators is represented by the following equations:

For men - BMR $=66.47+(13.7 \times$ Weight $)+$ (5 x Height) - (6.8 x Age) -2.3

\section{VO2max}

Also known as maximal oxygen consumption, maximal oxygen uptake, peak oxygen uptake or maximal aerobic capacity. It is the maximum rate of $\mathrm{O} 2$ consumption measured during any physical operation (here implies to the weeding operation). The name is derived from V- volume, O2- oxygen and maxmaximum.VO2max is expressed in litres of oxygen per minute $(\mathrm{L} / \mathrm{min})$. It can also be expressed in $\mathrm{mL} / \mathrm{kg} \mathrm{min}$.

VO2max is determined in the research study by utilizing the Uth- Sorensen- OvergaardPedersen estimation, the equation is based on maximum and resting heart rates and proposed by a group of researchers from Denmark. It is given by:

VO2max $\approx($ HRmax / HRrest) $x 15.3 \mathrm{~mL} / \mathrm{kg}$ minute -2.4

This equation for $\mathrm{VO} 2 \mathrm{max}$ is applicable only for the subjects having age between 21 to51 only and it lies within the range of age taken in the present findings.

\section{AWL}

AWL stands for acceptable work load. It is equal to $35 \%$ of the VO2max of the subjects (for young Indian worker).

\section{Maximum heart rate}

In the concerned research, it was determined by utilizing the formula derived by Maritz et al., (1961). 
HRm $=220$-Age (years) -2.5

\section{Energy Expenditure Rate (EER)}

EER is determined and estimated using the following formula proposed by Verghese et al., (1944) in studying the EER of the workers.

\section{EER $=0.159 \times$ Average heart rate $\mathbf{- 8 . 7 2}$} $(\mathrm{KJ} / \mathrm{min})-2.6$

\section{Oxygen Consumption Rate (OCR)}

Computed from the heart rate values (previously measured of the operator subject. OCR is represented by the equation (Singh et al., 2008) enumerated as follows:

\section{$\operatorname{OCR}(\mathrm{L} / \mathrm{min})=0.0114 \times$ HR $-0.68-2.7$}

\section{Cardiac cost of work (CCW)}

$\mathrm{CCW}$ is determined by employing the following relation: $\mathrm{CCW}=\mathrm{AHR} *$ Duration of activity AHR = Average Heart Rate (beats $/ \mathrm{min}$ ) Duration of activity $=30$ minutes (weeding activity was performed for duration of $30 \mathrm{~min}$ in the present study work)

AHR $=$ Average working heart rate - Average resting heart rate

\section{$\mathbf{C C W}=\mathbf{A H R} \times$ Duration of activity -2.8}

\section{Body part discomfort score (BPDS)}

Corlett and Bishop (1976) technique was used to measure confined discomfort. In this method, the body of respondents is divided into 27 regions. Each body region was numbered differently to avoid a subject marking on body region only. The subject was asked to mention to all body parts with discomfort, starting with the most painful, the next painful in descending order till no further areas are referred. In the present research, it was examined by proper investigating the level of fatigue for the selected subjects and by means of relation enumerated below (Corlett and Bishop, 1976):

\section{$\mathbf{B P D S}=\mathbf{S X} \mathbf{X}_{\mathbf{i}} \mathbf{S}(\mathbf{3 . 4 0})-2.9$}

where, $\mathrm{X}_{\mathrm{i}=}$ number of body parts and $\mathrm{S}=$ discomfort score (6 to 1 )

In the current research findings, the atmospheric conditions including average temperature, humidity and amount of sunshine was also assessed during the replications of the method taken in the month of February and March (as shown in the table 2.4).

The anthropometric data of the selected respondents was ascertained. The dimensions were measured by deploying anthropometer and measuring tape to maintain accuracy and preciseness in the results. Sixteen anthropometric measurements were taken, which were considered useful in utilizing the aforementioned tools. The corresponding strength data is enumerated in the table 2.5 given below:

\section{Statistical analysis employed}

The statistical analysis was considered to check the significant variation in the measured values with respect to ages of the respondents. The three replications were taken, and the values of average heart rate were deliberately examined by constructing the ANOVA in order to check the significance difference in the values with the mentioned ages. Split-plot design was employed during the research study. The coefficient of variance for the selected respondents was found to be 2.21. Since, the calculated variance ratio was slightly higher than its tabulated value, the alternative hypothesis was accepted which indicate that there is a significant variation in the working heart rate with different ages. 


\section{Results and Discussion}

The results obtained from the present investigation has been summarized in this chapter. The factors taken under consideration in this concern research study are analysed and the inferences has been drawn pertinent to various physical and physiological parameters. The study focuses on its objectives by producing the results and its concise discussions are enumerated under following heads:

\section{Regarding assessment of physical properties} of male subjects

The BMI values calculated for the subject of ages $25,30,35,40,45$ and 50 were found as $19.86,19.36,20.29,21.43,19.33$ and 21.95 respectively. The average value of BMI for the subjects of given ages were $20.37 \mathrm{~kg} / \mathrm{m}^{2}$. The average value calculated was found normal and lies between the standard values 18.525(WHO 2006).

The average LBM value of the selected respondents was found to be 43.22 for different ages 25-50 years. The calculated value of LBM of various enumerated ages were 45.87, 40.49, 45.16, 44.47, 41.86, 41.45 and 43.22 respectively.

The values pertaining to BMR for the subjects of aforesaid ages were calculated and were found to be 1477.57, 1328.77, 1425.67, 1390.37, 1238.07 and 1251.27 respectively. The average value calculated for the subjects was 1351.95 .

The VO2max values of the respondents lies between the range $26-29 \mathrm{~mL} / \mathrm{Kg} \mathrm{min}$ (as indicated in the table 3.1). The lower values of VO2max of male subjects were encountered(VO2max $<38$ for men of ages between 20-29 is considered low - Astrand1960).
The acceptable work load for Indian worker is about $35 \%$ of VO2max. Hence, for the mentioned values of VO2max, the AWL of male respondents having age 25,30,35,40,45 and 50 were $9.76,9.86,9.97,9.80,8.95$ and 9.3 respectively.

\section{Regarding assessment of physiological parameters of the respondents}

The average resting heart rate of the male respondents of age 25, 30,35,40,45 and 50 was found to be 104, 101, 98, 95,105 and 99 respectively. Therefore, the average value of resting heart rate of the subjects was 100.33 bpm before carrying out the operation(weeding) by hand hoe. In case of wheel hoe, it was $100.5 \mathrm{bpm}$ as illustrated in the table 3.2.

\section{Reason for the increase in resting heart rate for wheel hoe}

An approximate increase in the average resting heart rate for wheel hoe might be due to initial weeding activity carried out by hand hoe for 20 minutes duration and then the subjects were allowed to take the required rest so that they could proceed for operation by wheel hoe.

This might be the reason for the enhancement of the resting heart rate when operation was conducted by wheel hoe.

The average working heart rate was measured for the respondents during accomplishment of work after 20 minutes duration. During the weeding operation conducted by hand hoe, the values of average working heart rate of male respondents of ages 25, 30, 35, 40, 45 and 50 were recorded as 116, 111, 110, 108, 119, and 110 (bpm) respectively and 115, 107, 109, 104, 111 and 104(bpm) respectively in case of weeding activity performed by wheel hoe. 
Comparison of average working heart rate for weeding operation conducted by hand and wheel hoe

The mean value calculated of average working heart rate for male subjects sustaining weeding activity by hand hoe and wheel hoe was 112.33 and $108.33(\mathrm{bpm})$ respectively.

By estimating the average heart rate value, the EER was calculated which is represented by the equation 3.6. For male respondents of the mentioned ages, the EER values when task was conducted by hand hoe were $8.77,8.13$, $7.82,7.42,9.09,7.40$ and8.19 (kJ/ min) respectively. While the EER values calculated for wheel hoe were 8.83,7.74, 7.58, 7.18, 8.61 and $7.34(\mathrm{~kJ} / \mathrm{min})$ respectively. Therefore, the average value of EER for male subjects during weeding operation conducted by hand and wheel hoe were 8.19 and $7.88(\mathrm{~kJ} / \mathrm{min})$ respectively.

The values of OCR were calculated as 0.57 , $0.53,0.51,0.48,0.60,0.51$ and $0.53(\mathrm{~L} / \mathrm{min})$ respectively when the subject accomplishes the weeding activity for the given duration of 20 minutes by hand hoe. However, in case of activity conducted by wheel hoe for the same subject of the above enlisting age, the readings were calculated as $0.58,0.50,0.49,0.46,0.56$ and $0.47(\mathrm{~L} / \mathrm{min}$ ) respectively. The average OCR was 0.53 and $0.41(\mathrm{~L} / \mathrm{min})$ for hand hoe and wheel hoe respectively. The OCR was slightly enhanced when the subjects carried out the work by hand hoe than by wheel hoe.

The CCW values, when task was conducted by hand hoe were 240, 200, 240, 260, 280 and 220 (beats) respectively for the enumerated ages. While the CCW values calculated for wheel hoe were $180,140,260,160,80$, and 120 (beats) respectively. Therefore, the average value of $\mathrm{CCW}$ of the respondents during weeding operation conducted by hand and wheel hoe were 240 and 156.67 (beats) respectively. The cardiac cost of work was maximum when the subjects carried out the work by hand hoe rather than by wheel hoe. Similar results were observed in the study conducted by Verma S. et al., (2011). The average BPDS values of selected subjects were ascertained as 25.4and 21.4 for hand hoe and wheel hoe respectively as enumerated in the table. Similar results were investigated by Kumar et al., 2002. The majority of body discomfort experienced were fatigue in knee and shoulder while it was arm, knee, wrist and shoulder in case of weeding operation conducted by hand hoe owing to the large effort required by the arms to uproot the weeds. However, for wheel hoe, the subjects undergoes lassitude which might be due to the high temperature of the surrounding ambience.

It was investigated that wheel hoe was efficiently designed and its sharp tynes offers little effort to remove the weeds. Thereby, it is concluded that wheel hoe offers easy adaptability and consistency in accomplishing the weeding activity in standing posture rather than the difficulty in manipulating the hand hoe in squatting position.

\section{Regarding assessment of physical properties of male subjects}

From the estimated values of LBM, the percentage of LBM in the body weights for male subjects of ages $25,30,35,40,45$ and 50 was found to be $78 \%, 83 \%, 81 \%, 78 \% 81 \%$ and $77 \%$.The percentage of male subjects lies above $75 \%$.So, it may be concluded that all male subjects of given ages were physically fit and healthy for performing the farm operation. They have perfect values of average LBM (as stated by National Academy of Sports Medicine 2006).

Reason for the declination of VO2max in male subjects - Consumption of alcohol, smoking and chewing of tobacco might be the reason for the declination of VO2max. Cardiac 
efficiency is reduced as the VO2max declines. Smoking reduces work capacity by reducing the oxygen carrying capacity of the blood.

Before the research study, the past history of the respondents was taken into consideration.
Above all, it is concluded that $\mathrm{VO} 2 \mathrm{max}$ declines as the age progresses. Also in the presented findings, the average value of VO2max of male respondents was found to be $30.16 \mathrm{~mL} / \mathrm{Kg}$. $\mathrm{min}$.

Table.1 The concise outlook of the experimental plan is enumerated in the mentioned table

\begin{tabular}{|l|l|}
\hline Brief outlook of the experimental plan & \\
\hline Farm operation & Weeding \\
\hline Implements used & Hand hoe and wheel hoe \\
\hline Total number of operators & 60 \\
\hline Total number of replications & 3 \\
\hline Duration of weeding activity & $30 \mathrm{~min}$ \\
\hline Area under weeding operation & $30 \times 40 \mathrm{~m}^{2}$ \\
\hline Area of the row(strip) under weeding operation & $0.5 \times 30 \mathrm{~m}^{2}$ \\
\hline ANOVA - Type & Split plot design \\
\hline
\end{tabular}

Table.2 Enlistment of materials requirement for implementing the experimental plan

\begin{tabular}{|l|l|l|l|}
\hline S. No & Characterstics & Variable & Equipments/ Tools \\
\hline 1. & $\begin{array}{l}\text { Anthropometric } \\
\text { dimensions }\end{array}$ & $\begin{array}{l}\text { For measurement of small } \\
\text { and large body dimensions }\end{array}$ & $\begin{array}{l}\text { Anthropometer, steel scale, } \\
\text { measuring tape }\end{array}$ \\
\hline 2. & $\begin{array}{l}\text { Physical } \\
\text { variables }\end{array}$ & Weight & Weighing balance \\
\hline 3. & $\begin{array}{l}\text { Physiological } \\
\text { responses }\end{array}$ & Pulse rate & $\begin{array}{l}\text { Electronic sphygmomanometer, } \\
\text { pulse oximeter }\end{array}$ \\
\hline \multicolumn{2}{|l|}{ Implements for carrying out weeding operation- Hand hoe (khurpi) and Wheel hoe } \\
\hline
\end{tabular}

Table.3 illustrating the features of weeding implements

\begin{tabular}{|l|l|l|l|l|}
\hline \multicolumn{5}{|l|}{ Specifications and working features of the mentioned weeding implements } \\
\hline S.no & Hand hoe (khurpa) & Wheel hoe & 1680 \\
\hline $\mathbf{1}$ & Overall length $(\mathrm{mm})$ & 320 & Overall length $(\mathrm{mm})$ & $110-180$ \\
\hline $\mathbf{2}$ & Width of cutting edge $(\mathrm{mm})$ & 120 & Width of cutting edge $(\mathrm{mm})$ & 150 \\
\hline $\mathbf{3}$ & Length of the blade $(\mathrm{mm})$ & 220 & Length of the blade $(\mathrm{mm})$ & 7.4 \\
\hline $\mathbf{4}$ & Weight $(\mathrm{kg})$ & 1.1 & Weight $(\mathrm{kg})$ & \\
\hline
\end{tabular}

Table.4 Enumeration of operating conditions

\begin{tabular}{|l|l|l|}
\hline S. No & Operational parameters & Values \\
\hline 1. & Average temperature, ${ }^{0} \mathrm{C}$ & 34 \\
\hline 2. & Average humidity, $\%$ & 52 \\
\hline 3. & Average sunshine, hours & 8.4 \\
\hline
\end{tabular}


Table.5 The anthropometric data of the male respondents

\begin{tabular}{|l|l|l|l|l|l|l|l|}
\hline S. No. & $\begin{array}{l}\text { Anthropometric \& } \\
\text { data }\end{array}$ & Strength & \multicolumn{9}{l}{ Age of male operators } \\
\hline & & 25 & 30 & 35 & 40 & 45 & 50 \\
\hline $\mathbf{1}$ & Weight (kg) & 53 & 49 & 56 & 57 & 48 & 54 \\
\hline $\mathbf{2}$ & Height & 171 & 159 & 166 & 163 & 164 & 157 \\
\hline $\mathbf{3}$ & Elbow height & 105 & 98 & 102 & 101 & 101 & 97 \\
\hline $\mathbf{4}$ & Olecranon height & 99 & 95 & 97 & 94 & 95 & 93 \\
\hline $\mathbf{5}$ & Illiocrystable height & 91 & 89 & 90 & 85 & 90 & 87 \\
\hline $\mathbf{6}$ & Illiospinal height & 149 & 130 & 147 & 145 & 146 & 130 \\
\hline $\mathbf{7}$ & Knee height & 50 & 45 & 47 & 46 & 46 & 43 \\
\hline $\mathbf{8}$ & Arm reach & 81 & 76 & 77 & 76 & 75 & 73 \\
\hline $\mathbf{9}$ & Vertical reach & 199 & 197 & 204 & 201 & 203 & 196 \\
\hline $\mathbf{1 0}$ & Hand length & 19 & 16 & 18 & 18 & 17 & 16 \\
\hline $\mathbf{1 1}$ & Head length & 20 & 19 & 20 & 19 & 19 & 18 \\
\hline $\mathbf{1 2}$ & Foot length & 24 & 22 & 25 & 24 & 23 & 22 \\
\hline $\mathbf{1 3}$ & Biacromial breadth & 40 & 38 & 39 & 38 & 39 & 37 \\
\hline $\mathbf{1 4}$ & Bideltoid breadth & 46 & 44 & 45 & 45 & 44 & 43 \\
\hline $\mathbf{1 5}$ & Acromial height & 141 & 136 & 138 & 137 & 140 & 132 \\
\hline $\mathbf{1 6}$ & Eye height & 161 & 150 & 158 & 152 & 151 & 149 \\
\hline
\end{tabular}

(Measurement taken in $\mathrm{cm}$ unless otherwise specified)

Table.6 Depicting the physical characteristics of the selected respondents

\begin{tabular}{|l|l|l|l|l|l|l|l|l|}
\hline S.no & $\begin{array}{l}\text { Physical } \\
\text { characteristics }\end{array}$ & \multicolumn{3}{l}{ Age (years) } & \multicolumn{4}{ll}{ Average } \\
\hline $\mathbf{1}$ & Age (years) & 25 & 30 & 35 & 40 & 45 & 50 & \\
\hline $\mathbf{2}$ & Height (cm) & 171 & 159 & 166 & 163 & 164 & 157 & $\mathbf{1 6 3 . 3 3}$ \\
\hline $\mathbf{3}$ & Weight (kg) & 58 & 49 & 56 & 57 & 52 & 54 & $\mathbf{5 4 . 3 3}$ \\
\hline $\mathbf{4}$ & BMI (kg/m $\mathbf{2})$ & 19.86 & 19.36 & 20.29 & 21.43 & 19.33 & 21.95 & $\mathbf{2 0 . 3 7}$ \\
\hline $\mathbf{5}$ & LBM & 45.87 & 40.49 & 45.16 & 44.47 & 41.86 & 41.45 & $\mathbf{4 3 . 2 2}$ \\
\hline $\mathbf{6}$ & BMR & 1477.57 & 1328.77 & 1425.67 & 1390.37 & 1238.07 & 1251.27 & $\mathbf{1 3 5 1 . 9 5}$ \\
\hline $\mathbf{7}$ & $\begin{array}{l}\text { VO2 } \mathbf{m a x} \\
\text { (mL/Kg.min) }\end{array}$ & 31.82 & 32.34 & 34.05 & 29.45 & 27.97 & 25.3 & $\mathbf{3 0 . 1 6}$ \\
\hline $\mathbf{8}$ & AWL & 9.76 & 9.86 & 9.97 & 9.8 & 8.95 & 9.3 & $\mathbf{9 . 6 1}$ \\
\hline
\end{tabular}


Table.7 The assessment of physiological responses $f$ the male respondents conducting weeding operation by hand hoe and wheel hoe

\begin{tabular}{|c|c|c|c|c|c|c|c|c|}
\hline \multicolumn{9}{|c|}{ I . By hand hoe (khurpa) } \\
\hline \multirow[t]{2}{*}{ S.n } & \multirow[t]{2}{*}{ Physiological parameters } & \multicolumn{6}{|c|}{ Age (years) } & \multirow[t]{2}{*}{ Average } \\
\hline & & 25 & 30 & 35 & 40 & 45 & 50 & \\
\hline 1 & Average resting heart rate(bpm) & 104 & 101 & 98 & 95 & 105 & 99 & 100.33 \\
\hline 2 & Average working heart rate (bpm) & 116 & 111 & 110 & 108 & 119 & 110 & 112.33 \\
\hline 3 & Average heart rate(bpm) & 12 & 10 & 12 & 13 & 14 & 11 & 12 \\
\hline 4 & Mean heart rate(bpm) & 110 & 106 & 104 & 101. & 112 & 104. & 106.3 \\
\hline 5 & Maximum heart rate (bpm) & 189 & 186 & 182 & 179 & 175 & 172 & 180.75 \\
\hline 6 & Energy Expenditure Rate (kJ/min) & 8.77 & 8.13 & 7.82 & 7.42 & 9.09 & 7.4 & 8.19 \\
\hline 7 & Oxygen Consumption Rate & 0.57 & 0.53 & 0.51 & 0.48 & 0.6 & 0.51 & 0.53 \\
\hline 8 & Cardiac Cost of Work(beats) & 240 & 200 & 240 & 260 & 280 & 220 & 240 \\
\hline \multicolumn{9}{|c|}{ II. By wheel hoe } \\
\hline \multirow[t]{2}{*}{ S.n } & Physiological parameters & \multicolumn{6}{|c|}{ Age (years) } & Average \\
\hline & & 25 & 30 & 35 & 40 & 45 & 50 & \\
\hline 1 & Average resting heart rate (bpm) & 106 & 100 & 96 & 96 & 107 & 98 & 100.5 \\
\hline 2 & Average working heart rate(bpm) & 115 & 107 & 109 & 104 & 111 & 104 & 108.33 \\
\hline 3 & Average heart rate(bpm) & 9 & 7 & 13 & 8 & 4 & 6 & 7.83 \\
\hline 4 & Mean heart rate(bpm) & 110.5 & 103.5 & 102.5 & 100 & 109 & 101 & 104.42 \\
\hline 5 & Maximum heart rate (bpm) & 189.5 & 186 & 182.5 & 179 & 175.5 & 172 & 180.75 \\
\hline 6 & Energy Expenditure Rate (kJ/min) & 8.85 & 7.74 & 7.58 & 7.18 & 8.61 & 7.34 & 7.88 \\
\hline 7 & Oxygen Consumption Rate & 0.58 & 0.5 & 0.49 & 0.46 & 0.56 & 0.47 & 0.51 \\
\hline 8 & Cardiac Cost of Work(beats) & 180 & 140 & 260 & 160 & 80 & 120 & 156.67 \\
\hline
\end{tabular}

Table.8 Assessment of average BPDS of the female operators in various farm operations

\begin{tabular}{|l|l|l|l|l|l|l|l|l|}
\hline $\begin{array}{l}\text { S. } \\
\text { No }\end{array}$ & Operations & \multicolumn{6}{|c|}{ Average body part discomfort score (BPBS) } \\
\hline & & $\mathbf{2 5}$ & $\mathbf{3 0}$ & $\mathbf{3 5}$ & $\mathbf{4 0}$ & $\mathbf{4 5}$ & $\mathbf{5 0}$ & Average \\
\hline 1. & Weeding by hand hoe & 23.50 & 23.90 & 24.75 & 25.65 & 26.85 & 28.70 & $\mathbf{2 5 . 4}$ \\
\hline 2. & Weeding by wheel hoe & 20.25 & 20.90 & 21.15 & 21.75 & 22.35 & 22.50 & $\mathbf{2 1 . 4}$ \\
\hline
\end{tabular}


Fig. 2(a) Hand hoe (khurpa)

Fig. 2(b) Wheel hoe

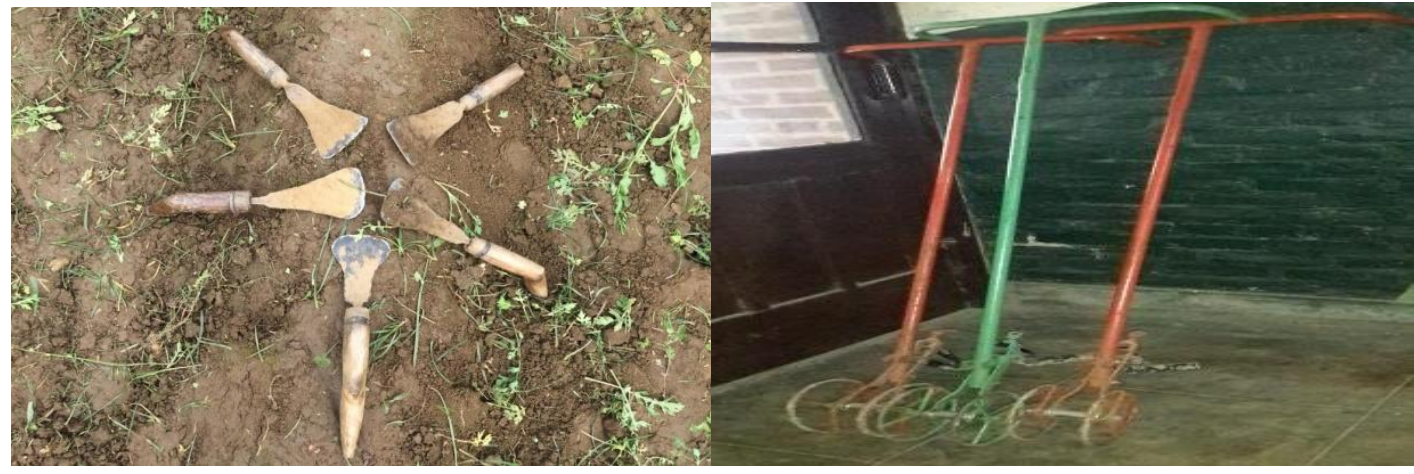

Fig.3-The operators undergoing weeding operation by hand hoe and wheel hoe

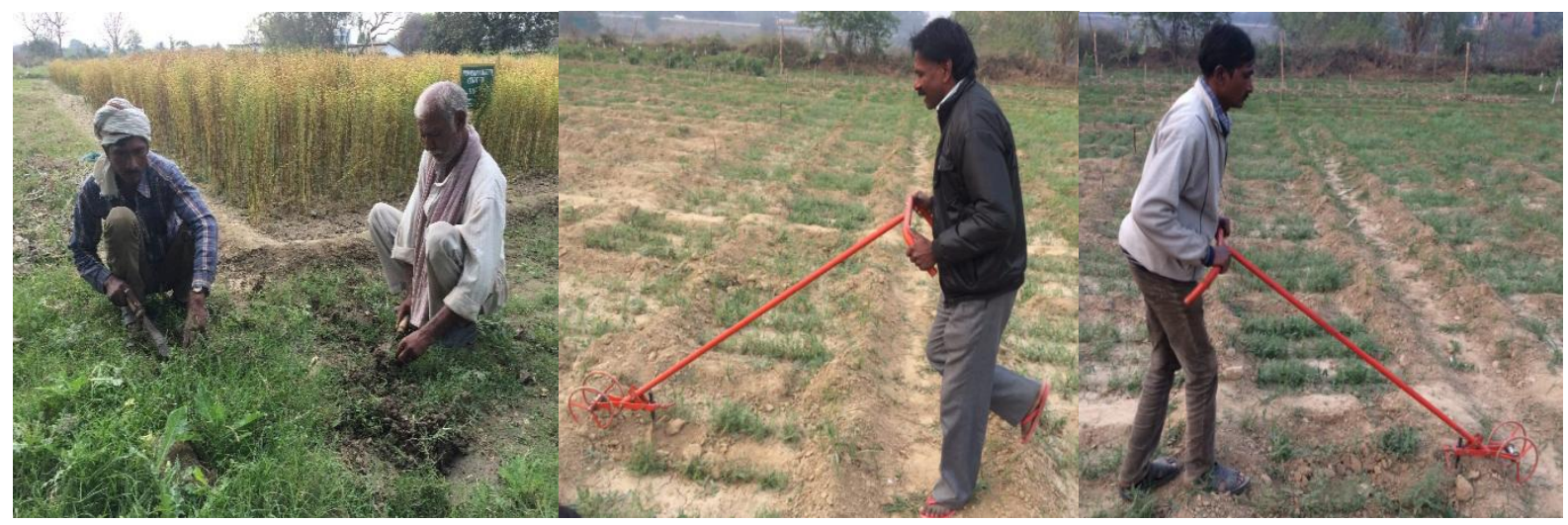

Fig: 4- Depicting the measurement of physical and physiological variables of operator

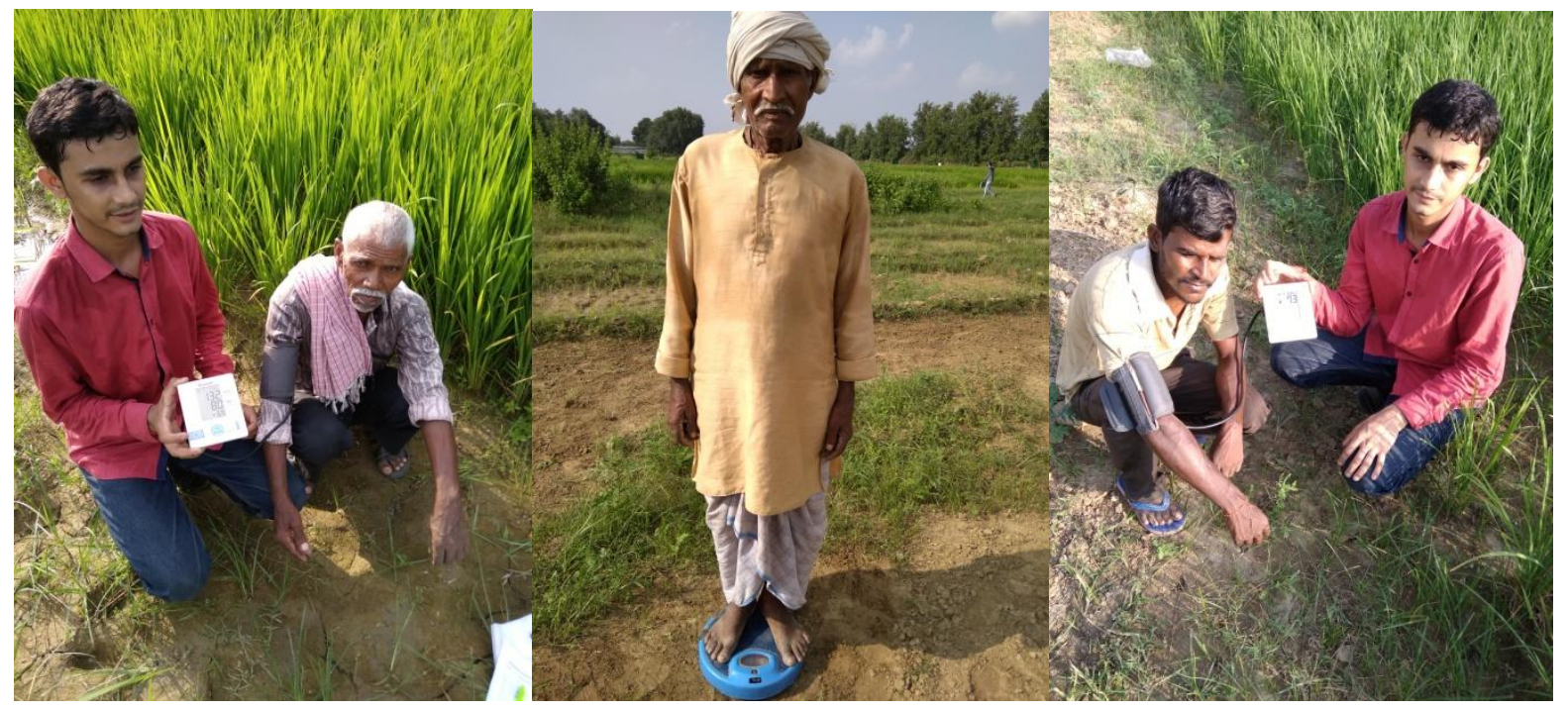


Regarding assessment of physiological parameters of the respondents

For the physiological responses, the male respondents were more comfortable physiologically in the standing posture i.e. in wheel hoe rather than by hand hoe from ergonomic point of view. The pulse rate was investigated high for the respondents employing hand hoe which might be due to the much effort required and prevailing operating conditions.

The health issues associated with the operators have their direct impact on their pulse rate while accomplishing the weeding activity.

The current findings investigates that the oxygen consumption rate was higher for the respondents employing hand hoe than by wheel hoe. As the fatigue rate was high among the respondents carrying out the task using the former implement, the oxygen consumption was slightly increased as the age of the operators progresses.

The energy expenditure rate was maximum when the subject carried out the work by hand hoe rather than by wheel hoe. This might be due to the inconvenience caused in continuing the work in squatting posture and the inconsistency while employing hand hoe.

Also, the prevailing conditions during the bright sunshine might be the reason for high energy consumption.

\section{The present analysis}

Regarding assessment of body part discomfort score of the respondents

The body discomfort arising were fatigue in knee and shoulder while it was arm, knee, wrist and shoulder in case of weeding operation conducted by hand hoe owing to the large effort required by the arms to uproot the weeds. It was investigated that wheel hoe was efficiently designed and its sharp tynes offers little effort to remove the weeds. Thereby, it is concluded in the research findings that wheel hoe offers easy adaptability and consistency in accomplishing the weeding activity in standing posture rather than the difficulty in manipulating the hand hoe in squatting position.

The study regarding assessing of anthropometrical, physical and physiological parameters of the male respondents during weeding operation by hand hoe and wheel hoe was successfully accomplished. The variations in the physical and physiological characteristics were noticed. The physiological parameters including resting and working heart rates, blood pressure, energy expenditure rate, oxygen consumption rate and cardiac cost of work of the concerned subject were assessed and the respondents exhibits significant variations during their association in the operation conducted by hand hoe and wheel hoe.

The subjects undergo light physical work in case of wheel hoe and moderately heavy physical work in hand hoe. The subjects performed the activity more compatible by wheel hoe than by hand hoe which might be due to their consistency and easy adaptability with the former implement in hard soil conditions. The latter implement required more effort on the shoulders of the subjects in the prevailing soil conditions which resulted increase in body discomfort and physiological variations.

\section{Acknowledgements}

The authors acknowledge the productive support of the professors of the farm machinery and power engineering department who guided in every path of the concern research study. Special mention to the farmers who perfectly coordinated the study during the prescribed duration of time. 


\section{References}

Agarwal S. (2007). Gender involvement in Farm Mechanization Issues for Extension and Research, NRC for women in Agriculture, Bhubaneshwar, India, Gite Vol II.

Corlett, E.N. and Bishop, R.P. 1976. A technique for assessing postural discomfort.

Ergonomics,19: 175-182. Heart rate during transition from rest to exercise in relation to exercise tolerance.Journal of Applied Physiology, 19: 857-862.

Kumar A., Haribabu B., and A. Srinivasa Rao. (2013). Ergonomical evaluation of manually operated weeder under wet land condition, 8(6): 249-255 Astrand. ACTA PhysiolScand 49 (Suppl); VO2max Norms 169:1960. Reprinted with permission from Blackwell Scientific Publications LTD.

Martitz, J.S., Morrison, J.F., Peter, J., Strydom, N.B. and Whyndham, C.H. (1961). A practical method of estimating individual's maximal oxygen uptake. Ergonomics, 4: 97.

Nag, P.K. and Dutt, P. (1979).Effectiveness of some simple agricultural weeders with reference to physiological responses.J. Human Ergology, 8 (1): 13-21.
Nag, P.K. and Dutt, P. (1979). Cardiorespiratory efficiency in some agricultural work.Appl. Ergonomics, 11 (2): 81-84.

Saha, P.N. (1976). The practical use of some physiological research methods for assessment of work stress. J. Indian Assoc. Physiotherapists, 4: 9-13.

Sam B. (2015). Ergonomic evaluation of paddy seeder and rotary with female operators.Farming Systems Research Station, Kerala Agricultural University, Sadanandapuram, Kottarakkara, Kerala, India

Tiwari, V.K., Datta, R.K. and Murthy, A.S.R. (1991). Evaluation of three manually operated weeding devices. Applied Ergonomics, 22: 111-116.

Varghese, M.A., Saha, P.N. and Atreya, N. (1994). A rapid appraisal of occupational workload from a modified scale of perceived exertion. Ergonomics, 37 (3): 485-491.

Uth, N., Sorensen, H., Overgaard, K., Pendersen, P.K.,2005. Estimation of VO2max from the ratio between HRmax and HRmin- the heart rate ratio method. Eur. J Appl. Physiol., January;93(4): 508-9.

World Health Organization (2006) "BMI Classification".Global Database on Body Mass Index.

\section{How to cite this article:}

Vishnu Ji Awasthi, Manpreet Singh, RajatMishra, Rahul Chaudhary, Mirtunjay Pandey, Dilwar Singh Parihar, Shubham Gautam and Dhiraj Kumar 2019. Ergonomic and Workload Assessment in Weeding Operation Conducted for Wheat Crop for Male Respondents. Int.J.Curr.Microbiol.App.Sci. 8(09): 2597-2609. doi: https://doi.org/10.20546/ijcmas.2019.809.301 